\title{
Bonding of Boride Base Hard Alloys on Structural Parts*
}

\section{Introduction}

New types of cermets, KH alloys, have been developed by Toyo Kohan. KH alloys are boride base hard alloys consisting of a hard phase and iron base binder phase containing $\mathrm{Cr}$ and $\mathrm{Ni}$, and are produced by liquid phase sintering. The alloys have good mechanical properties and excellent wear and corrosion resistance. Therefore, they are utilized as wear resistant parts and tools in various fields of industrial applications.

As wear resistance in many practical situations is required for limited portions of a structural part, wear resistant materials are selectively bonded to the part subject to wear. In this regard, $\mathrm{KH}$ alloys can be joined to steels by diffusion bonding as well as soldering. Bond of a green compact or a green sheet of $\mathrm{KH}$ to steels is possible by sinter bonding.

\section{Features of Bonded $\mathrm{KH}$ on Steels}

Table 1 shows the characteristics of typical $\mathrm{KH}$ alloys. The thermal expansion coefficients of $8.9 \times$ $10^{-6} /{ }^{\circ} \mathrm{C}$ and $9.3 \times 10^{-6} /{ }^{\circ} \mathrm{C}$ are close to those of steels and, therefore, guarantee excellent bonding between $\mathrm{KH}$ and steels.

Figure 1 shows the microstructure of the interface between $\mathrm{KH}$ V40 and JIS STB 42 joined by sinter bonding, indicating an ideal junction without defects such as pores. The strength of a diffusion bonded junction of $\mathrm{KH}$ and mild steel (JIS-SS41) is also shown in Table 1. The shear strength was measured by the procedure described in JIS G 0601. Strengths over $40 \mathrm{kgf} / \mathrm{mm}^{2}$ were obtained, which are higher than that of $\mathrm{Ag}$ soldering.

\section{Applications}

$\mathrm{KH}$ hard alloys are used for wear and corrosion resistant can making tools, resin injection molding machine parts, hot copper extrusion dies, bearings in molten zinc baths, non-lublicant bearings, and protective tube linings for boilers.

Diffusion and sinter bonding are applied successfully in many of these applications, reducing the costs for $\mathrm{KH}$ applications and assuring a long life of materials, especially at high temperatures $\left(900^{\circ} \mathrm{C}\right)$.

\section{Conclusions}

(1) Since $\mathrm{KH}$ alloys are iron containing boride base hard alloys, the bonding between $\mathrm{KH}$ and steels is mainly effectuated by $\mathrm{Fe}-$ $B$ eutectic liquid phase.

(2) The bonding strength is high enough for applications to structural parts.

(3) In many applications, $\mathrm{KH}$ can be bonded by the diffusion or sintering methods to the portions of structural parts where wear resistance is required.

Table 1. Characteristics of KH.

\begin{tabular}{lcc}
\hline \multicolumn{1}{c}{ Grade } & KH-V 30 & KH-V40 \\
\hline Density $\left(\mathrm{g} / \mathrm{cm}^{3}\right)$ & 8.2 & 8.2 \\
Hardness (HRA) & $88 \sim 90$ & $86 \sim 88$ \\
Transverse rupture strength & $210 \sim 240$ & $220 \sim 250$ \\
$\quad\left(\mathrm{kgf} / \mathrm{mm}^{2}\right)$ & & \\
Linear thermal expansion & $8.9 \times 10^{-6}$ & $9.3 \times 10^{-6}$ \\
$\quad$ coefficient $\left(\mathrm{RT} \sim 800^{\circ} \mathrm{C}\right)$ & & \\
$\begin{array}{c}\text { Shear strength }\left(\mathrm{kgf} / \mathrm{mm}^{2}\right) \\
\quad(\text { diffusion bonded KH } \\
\text { with SS41) }\end{array}$ & 42.6 & 43.7 \\
\hline
\end{tabular}

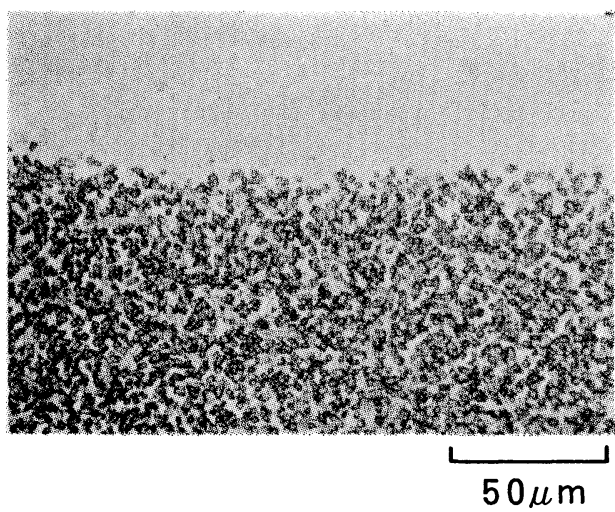

Fig. 1. Sinter bonded interface between V40 and STB42.

\footnotetext{
* For further information, write to New Product Development Department, Toyo Kohan Co., Ltd., 1302 Higashitoyoi, Kudamatsu, Yamaguchi Pref. 744. (C) 1987 ISIJ
} 